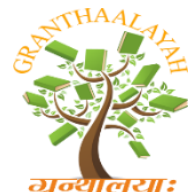

INTERNATIONAL JOURNAL OF RESEARCH GRANTHAALAYAH A knowledge Repository

Science

\title{
IN SILICO STUDIES OF SOPHORAFLAVANONE G: QUANTUM CHARACTERIZATION AND ADMET
}

\author{
David Lopes Santiago de Oliveira ${ }^{1}$, Emanuelle Machado Marinho ${ }^{2}$, Francisco Nithael \\ Melo Lucio ${ }^{1}$, Marcia Machado Marinho ${ }^{3}$, Francisco Rogênio Da Silva Mendes ${ }^{1}$, \\ Emmanuel Silva Marinho *1 \\ ${ }^{1}$ Chemistry Department, State University of Ceará, Brazil \\ ${ }^{2}$ Department of Analytical Chemistry and Physical-Chemistry, Federal University of Ceará, \\ Brazil \\ ${ }^{3}$ Department of Clinical and Toxicological Analysis, Federal University of Ceará, Brazil
}

\begin{abstract}
Currently, the search for new drugs with greater therapeutic potential and less side effects has been fostered by the advancement of the use of molecular modeling drugs, which in addition to supporting the full characterization of the molecule, allow simple algorithms to predict pharmacokinetic. In this context the present work aimed to perform the electronic / structural characterization, to evaluate the pharmacokinetic properties and to perform a virtual screening of the possible biological targets of Sophoraflavonone G, a promising flavonone, which presents several pharmacological properties. Sophoraflavanone G was geometrically optimized by semiempirical quantum calculations, plot the MESP, identifying the nucleophilic sites. Using the boundary orbitals, it was possible to identify a greater tendency for electron donation in relation to Naringeni, with lower ionization potential, higher hardness and less softness. With respect to pharmacokinetics Sophoraflavonone $G$ confirmed the safety of the compound for oral administration with good skin permeability, which allows applications in topical formulations. Presents indications for gastro intestinal absorption, as for possible interactions with biological targets, interaction with the estrogen receptor alpha, sodium / glucose co-transporter 2, betasecretase 1 , cyclooxygenase-1.The data obtained from an early stage for a comparative analysis between its analogues and fundamental for future studies of relationships between the threedimensional structure of Sophoraflavanone $\mathrm{G}$ and its biological activities.
\end{abstract}

Keywords: ADMET; Flavonone; Pharmacokinetic; Quantum Study; Semi-Empirical; S. Flavescens.

Cite This Article: David Lopes Santiago de Oliveira, Emanuelle Machado Marinho, Francisco Nithael Melo Lucio, Marcia Machado Marinho, Francisco Rogênio Da Silva Mendes, and Emmanuel Silva Marinho. (2019). "IN SILICO STUDIES OF SOPHORAFLAVANONE G: QUANTUM CHARACTERIZATION AND ADMET." International Journal of Research - Granthaalayah, 7(11), 160-179. https://doi.org/10.29121/granthaalayah.v7.i11.2020.347. 


\section{Introduction}

Flavonoids are a class of secondary metabolites found in plants that perform a variety of functions. They are known as plant pigments mainly present in flower petals to attract pollinators and for their antioxidant activities, providing consumers with some hope for medicinal uses, potentially cancer treatment. [1].

The dried roots of the Sophora flavescens plant belonging to the Leguminosae family, is used in traditional Chinese medicine and has antibacterial [2], antiviral, antiprotozoal, anti-inflammatory [3], antipyretic [3], healing, anti-hemorrhagic, antimalarial [4], phospholipase-C $\gamma 1$ enzyme inhibiting activity [5], antiarrhythmic effects [6] used in the treatment of skin ulcers and also as an insecticide. In addition to flavonoids with regular prenyl side chains, S. flavescens also produces several flavanones with lavasulil chains, irregular monoterpenoid groups such as kurarinone and sophoraflavanone G [7], [8] noting that studies have shown the importance of the chain. side of Lavandulila for antitumor activity [9] Flavonoids isolated from this plant have phospholipase-C $\gamma 1$ inhibition activity [5].

Sophoraflavanone $\mathrm{G}$, one of the major flavanones isolated from the dried roots of S. flavescens, is known to possess antimalarial, antimicrobial, antiviral and antioxidant activities and inhibits the production of nitric oxide and prostaglandin E2 in lipopolysaccharide treated RAW cells. [10]. These biological activities are indicative of the pharmacological potential of Sophoraflavanone G.

Thus, with the development of chemistry, especially organic synthesis, many substances that have some kind of biological activity have been synthesized. As a result, drugs of synthetic origin became about $80 \%$ of the drugs on the market. Thus, many of these substances come from prototype structures found in natural products. Often, organic synthesis contributes not only to a greater production of the natural substance that has biological activity, but also to the structural modification of this substance to obtain pharmacologically superior products [11].

With the increase in computer processing potential and the development of more accurate mathematical algorithms, molecular modeling has been increasing the development of new drugs, reducing research costs through electronic and structural characterization, pharmacokinetic, toxicological simulations and receptor drug interactions, which make it possible with great precision to analyze the potential drug, predicting its potential, indicating the continuity or not of tests in vivo and in vitro[12][13][14][15].

Given the need for the development of new drugs, the aim of this study was to perform the electronic / structural characterization, evaluate the pharmacokinetic properties and perform a virtual screening of the possible biological targets of sophoraflavonone G. This study is a fundamental step for DRUG studies. design, molecular docking and molecular dynamics.

\section{Materials and Methods}

\section{Computational Details}

All the computations simulations were performed on personal computer with intel® Core TM i7 $7700 \mathrm{HQ}$ processor, 16 GB RAM, 4G Nvidia ${ }^{\circledR}$ GeForce GTX 1050 Radeon video card and 
Microsoft Windows $10 \AA$ as operating system. All softwares codes used are free license for academic use.

\section{Structural Optimization}

Initially, after the literature review, the two-dimensional molecular structure of Sophoraflavanone $\mathrm{G}$ from the ChemSpider ${ }^{\circledR}$ virtual repository (http://www.chemspider.com) (Figure 1A) was used to obtain the following data: nomenclatures, physicochemical properties and mechanisms of action. After obtaining the data in its two-dimensional form, the molecule was geometrically optimized by semi-empirical quantum calculations, implemented in the code ArgusLab® [16] configured with Hamiltonian Parametric Method 3 (PM3) parameters [17]. As Sophoraflavanone $\mathrm{G}$ is an analogue derivative of anagerin (Figure 1B), for comparative analysis, optimization data were used under the same conditions.

\section{Fronteir Orbitals, MESP and Descriptores Reactivity}

To start the reactivity study we need to obtain the spatial conformation (3D) of the molecule, because from it we can calculate the energies of the orbitals. In this context, the LCAO-MO Model used in the theory of molecular orbitals, which uses the linear combination of atomic orbitals, to generate the molecular orbitals, keeping the same number of orbitals and fundamental for rendering and identification of the orbitals. In terms of reactivity analysis we can highlight the homo and the lunar orbitals, which are called boundary orbitals, since from the energy difference among them we can identify the electron receptor or donor bias of the molecule [18][15][19].

Thus it was possible to obtain the lowest potential energy conformation of the molecule, characterizing HOMO (Higher Energy Busy Molecular Orbital) ( $\varepsilon_{\text {номо }}$ ), LUMO (Low Energy Unoccupied Molecular Orbital) ( $\varepsilon_{\text {LUMO }}$ ) [20] [21] [22] and the reactivity descriptors, GAP (Amount of energy required for the electron to transition), electron affinity (A), ionization potential (I), electronegativity $(\chi)$, hardness $(\eta)$, Chemical softness $(S)$, chemical potential $(\mu)$ and electrophilicity index $(\Omega)$ (Table 1) [23]follows [24][25][26][27][28][29]. In addition to the descriptors, heat of formation was calculated, Dipole Moment and MESP (Electrostatic Potential Surface Map) [30].Avogadro software was used to visualize the results and render 3D structures[31][32].

Table 1: Calculation Methodology for Reactivity Descriptors

\begin{tabular}{|c|c|}
\hline Descriptor & Formula \\
\hline GAP & $\mathrm{GAP}=\Delta \varepsilon=\left|\varepsilon_{\text {HOMO }}\right|-\left|\varepsilon_{\text {LUMO }}\right|$ \\
\hline Electron affinity $(\mathbf{A})$ & $\mathrm{A}=-\varepsilon_{\mathrm{LUMO}}$ \\
\hline Electronegativity $(\boldsymbol{\chi})$ & $\chi=(\mathrm{I}+\mathrm{A}) / 2$ \\
\hline Vertical Ionization potential $(\mathbf{I})$ & $\mathrm{I}=-\varepsilon_{\text {HOMO }}$ \\
\hline Chemical hardness $(\boldsymbol{\eta})$ & $\eta=(\mathrm{I}-\mathrm{A}) / 2$ \\
\hline Chemical softness $(\mathbf{S})$ & $\mathrm{S}=1 / 2 \eta$ \\
\hline chemical potential $(\boldsymbol{\mu})$ & $\mu=-(\mathrm{I}+\mathrm{A}) / 2$ \\
\hline Electrophilicity index $(\boldsymbol{\Omega})$ & $\omega=\mu^{2} / 2 \eta$ \\
\hline
\end{tabular}

The properties of Absorption, Distribution, Metabolization, Excretion and Toxicity (ADMET) including solubility, blood brain barrier (BBB), plasma protein binding, CYP2D6 binding, 
gastrointestinal absorption and hepatotoxicity were predicted using the Swissadme code (http: // www. swissadme.ch/), an online software written in JavaScript, HTML, and PHP5 with Python 2.7 encoded computing backend that allows you to accurately analyze $2 \mathrm{D}$ structures of drug candidates against ADMET descriptors [33][34][35]. lipophilicity was predicted according to Wildman et al [36], violations of oral bioavailability were assessed according to the Lipinski rule [37].At this stage we also examined the possible inhibitory character of Sophoraflavonone of Cytochrome Family (P450 CYP) isoforms such as CYP1A2 and CYP2D6, in addition to other pharmacokinetic predictions (gastrointestinal absorption, P-glycoprotein and blood brain barrier), as Ghose and Veber Rules and bioavailability [38] and Brain Or IntestineL EstimateD permeation method (BOILED-Egg) to predict gastrointestinal absorption predict gastrointestinal [39].

\section{D Structure Modeling}

The 2D Structural Models were designed in MarvinSketch code (ChemAxon Software) [40]and coded for SMILES in the SMILES online translator and generator structure file found in OpenBabel software [41].

\section{Virtual Screening for Target Classes}

To identify possible target proteins, Swiss Target Prediction [42][43] was used, an online script that uses the reverse trace scope to identify through structural similarities between molecules to similarly predict possible receptors (biological targets). Homo sapiens receiver search identifier [44], the Sophoraflavonone G two-dimensional structure was used, which was converted to 3D format, using the Tanimoto coefficient as an adjustment factor and similarity, vectorized by the Manhattan distance, defined by by the equation using the vectors ( $\mathrm{X}$ and $\mathrm{Y}$ ) and equation 2 to calculate the final value 3D similarity between molecules of $i$ and $j$, where $d$ ij is the shortest Manhattan distance between the $20 \times 20$ calculated distances over all possible conformations of each molecule [42].

$$
d=\sum_{s=1}^{18}\left|x_{n}-x_{s}\right|
$$

$1 /(1+1 / 18 d i j$

\section{Results and Discussions}

\section{Structural and Conformational Characterization}

Using Sophoraflavanone G's two-dimensional structure obtained from the Chewspider.com virtual repository (http://www.chemspider.com/Chemical-Structure.65766.html?rid=ee036cea-60454fad-82ca-0b7579f6a86f) (ID 65766) its name could be identified according to the International Union of Pure and Applied Chemistry IUPAC (2S) -2- (2,4-Dihydroxyphenyl) -5,7-dihydroxy-8 [(2R) -2-isopropenyl- 5-methyl-4-hexen-1-yl] -2,3-dihydro-4H-chromen-4-one and its molecular formula $\mathrm{C} 25 \mathrm{H} 28 \mathrm{O} 6$. In addition, physical and chemical properties could be obtained [Table 1], linked to the structural composition of the molecule, from which we can highlight its density (1.3 $\pm 0.1 \mathrm{~g} \mathrm{~cm}-3)$, its surface tension $(55.9 \pm 3.0$ dyne $\mathrm{cm}-1)$, molar volume $(335.3 \pm 3.0 \mathrm{~cm} 3)$ and their ability to form hydrogen bonds by determining atoms with the potential to receive or donate electrons in hydrogen bonds among other properties. 
Table 1: Physical-chemical properties of the Sophoraflavanone G

\begin{tabular}{|c|c|c|c|}
\hline Properties & Value & Properties & Value \\
\hline Molecular Formula & $\mathrm{C}_{25} \mathrm{H}_{28} \mathrm{O}_{6}$ & Monoisotopic Mass & $424.188599 \mathrm{Da}$ \\
\hline Density & $1.3 \pm 0.1 \mathrm{~g} / \mathrm{cm}^{3}$ & Refractive index & 1.623 \\
\hline Boiling point & $\begin{array}{c}659.3 \pm 55 ., 0{ }^{\circ} \mathrm{C}(760 \\
\mathrm{mmHg})\end{array}$ & Molar Refractivity & $118.2 \pm 0.3 \mathrm{~cm}^{3}$ \\
\hline Vapour Pressure & $0.0 \pm 2.1 \mathrm{mmHg}\left(25^{\circ} \mathrm{C}\right)$ & Superficial tension & $55.9 \pm 3.0 \mathrm{dyne} / \mathrm{cm}$ \\
\hline $\begin{array}{c}\text { Enthalpy of } \\
\text { Vaporization }\end{array}$ & $100.5 \pm 3.0 \mathrm{~kJ} / \mathrm{mol}$ & Molar Volume & $335.3 \pm 3.0 \mathrm{~cm}^{3}$ \\
\hline Receptors \#H & 6 & Donors \#H & 4 \\
\hline
\end{tabular}

Souce: Virtual Repository ChemSpider ${ }^{\circledR}[$ http://www.chemspider.com/Chemical-

Structure.65766.html?rid=1ac8c714-e4b9-4bfe-90ff-e237ec005803].

The two-dimensional structure of Sophoraflavanone $G$ (Figure 1B), available from the ChemSpider ${ }^{\circledR}$ repository, was in its ground state, presenting only the molecular formula $(\mathrm{C} 25 \mathrm{H} 28 \mathrm{O} 6)$ and the connectivity of atoms, with an easy to see initial conformation but with different potential energy. of the molecule in its native form. because the two-dimensional coordinates of a molecule available in an online repository are not necessarily in the most stable conformation [45]. Thus, to obtain more accurate calculations about the molecule and its more stable final conformation, we need to perform a geometric optimization using the energy minimization process [46]. This geometric optimization was performed using the semi-empirical quantum method formalism QM_PM3 (Parametric Method 3), performing uninterrupted cycles of 200 interactions, repeated until the structure reaches a point of lowest possible minimum energy, thus each of the atoms that the structure occupied its place of lowest energy in the system and the three-dimensional structure reached the most stable calculable point (Figure 2), presenting a spatial distribution that allows the lowest potential energy possible [47][48], making the potential energy of the molecule assumed a value of $(-118893.6623 \mathrm{kcal} / \mathrm{mol})$, no longer varying, reaching a stationary point of the energy surface [4], the formation heat $(-206.3487 \mathrm{kcal} / \mathrm{mol})$ and dipole moment $(\mu)$ in length. (4.95590298 debye) characterizing the molecule as polar. Some other properties of the structure are directly linked to the dipolar moment $(\mu)$, such as melting and boiling points and their solubility in water.
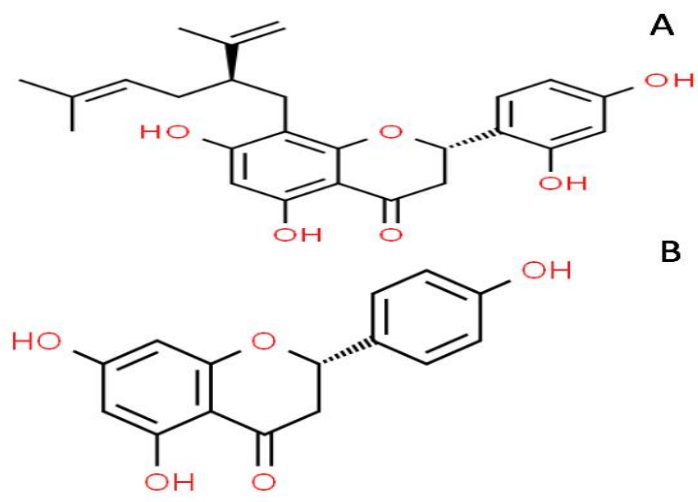

B

Figure1: The two-dimensional structure Sophoraflavanone G(A) Naringenin(B). Souce: Virtual Repository ChemSpider® 


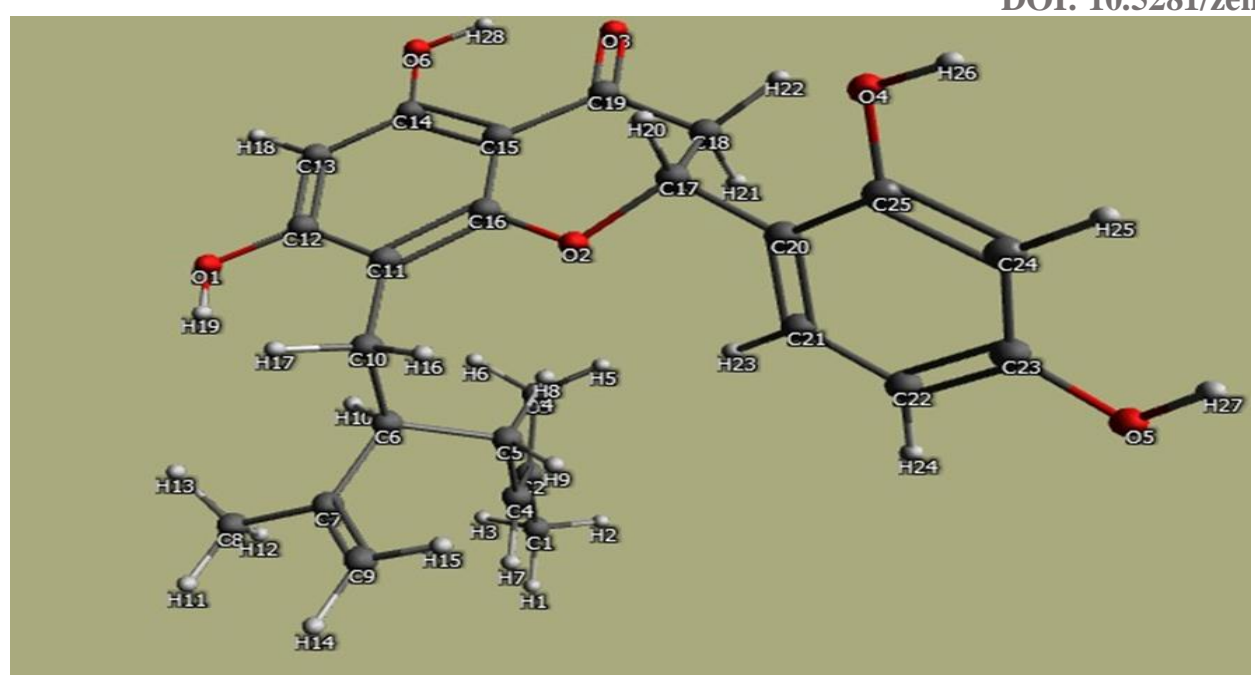

Figure 2: Optimized structure of Sophoraflavanone G

By obtaining the molecule in a theoretically more stable structure, it was possible to calculate the formal and partial charges of all atoms as well as their valence [49][50]. All atoms showed zero formal charge and significant variations in their partial charges were found, such as Hydrogen from 0.027 to 0.292 , Carbon from -0.099 to 0.174 and Oxygen from -0.507 to -0.292 . These data (table 2), especially valence, correspond to the literature, which serves to validate the results obtained. Despite the neutrality through optimization, it is possible to observe in the results obtained the largest and smallest (residual) partial loads. It was noticed that atoms 59, 58,57,50 $(\mathrm{H})$ and $30(\mathrm{O})$ presented larger and smaller partial charge respectively, charges from electrons being closer or farther from one of the bond atoms, taking with them charge.

Table 2: Atomic properties of the compound Sophoraflavanone G

\begin{tabular}{|c|c|c|c|c|}
\hline Atom & \multicolumn{2}{|c|}{ Element type } & Valencia & Partial change \\
\hline $\mathbf{1}$ & $\mathrm{C}$ & $\mathrm{C} 3$ & 4 & -0.044 \\
\hline $\mathbf{2}$ & $\mathrm{C}$ & $\mathrm{C} 2$ & 3 & -0.080 \\
\hline $\mathbf{3}$ & $\mathrm{C}$ & $\mathrm{C} 3$ & 4 & -0.044 \\
\hline $\mathbf{4}$ & $\mathrm{C}$ & $\mathrm{C} 2$ & 3 & -0.085 \\
\hline $\mathbf{5}$ & $\mathrm{C}$ & $\mathrm{C} 3$ & 4 & -0.028 \\
\hline $\mathbf{6}$ & $\mathrm{C}$ & $\mathrm{C} 3$ & 4 & -0.013 \\
\hline $\mathbf{7}$ & $\mathrm{C}$ & $\mathrm{C} 2$ & 3 & -0.076 \\
\hline $\mathbf{8}$ & $\mathrm{C}$ & $\mathrm{C} 3$ & 4 & -0.044 \\
\hline $\mathbf{9}$ & $\mathrm{C}$ & $\mathrm{C} 2$ & 3 & -0.099 \\
\hline $\mathbf{1 0}$ & $\mathrm{C}$ & $\mathrm{C} 3$ & 4 & -0.014 \\
\hline $\mathbf{1 1}$ & $\mathrm{C}$ & $\mathrm{Car}$ & 3 & 0.037 \\
\hline $\mathbf{1 2}$ & $\mathrm{C}$ & $\mathrm{Car}$ & 3 & 0.127 \\
\hline $\mathbf{1 3}$ & $\mathrm{C}$ & $\mathrm{Car}$ & 3 & 0.023 \\
\hline $\mathbf{1 4}$ & $\mathrm{C}$ & $\mathrm{Car}$ & 3 & 0.134 \\
\hline $\mathbf{1 5}$ & $\mathrm{C}$ & $\mathrm{Car}$ & 3 & 0.101 \\
\hline $\mathbf{1 6}$ & $\mathrm{C}$ & $\mathrm{Car}$ & 3 & 0.142 \\
\hline $\mathbf{1 7}$ & $\mathrm{O}$ & $\mathrm{O} 3$ & 2 & -0.506 \\
\hline $\mathbf{1 8}$ & $\mathrm{O}$ & $\mathrm{O} 3$ & 2 & -0.482 \\
\hline
\end{tabular}




\begin{tabular}{|c|c|c|c|c|}
\hline $\mathbf{1 9}$ & C & C 3 & 4 & 0.136 \\
\hline $\mathbf{2 0}$ & C & C 3 & 4 & 0.052 \\
\hline $\mathbf{2 1}$ & C & C & 3 & 0.174 \\
\hline $\mathbf{2 2}$ & O & O 2 & 1 & -0.292 \\
\hline $\mathbf{2 3}$ & C & Car & 3 & 0.035 \\
\hline $\mathbf{2 4}$ & C & Car & 3 & -0.048 \\
\hline $\mathbf{2 5}$ & C & Car & 3 & -0.020 \\
\hline $\mathbf{2 6}$ & C & Car & 3 & 0.120 \\
\hline $\mathbf{2 7}$ & C & Car & 3 & 0.022 \\
\hline $\mathbf{2 8}$ & C & Car & 3 & 0.127 \\
\hline $\mathbf{2 9}$ & O & O3 & 2 & -0.506 \\
\hline $\mathbf{3 0}$ & O & O 3 & 2 & -0.507 \\
\hline $\mathbf{3 1}$ & O & O 3 & 2 & -0.506 \\
\hline $\mathbf{3 2}$ & H & H & 1 & 0.027 \\
\hline $\mathbf{3 3}$ & H & H & 1 & 0.027 \\
\hline $\mathbf{3 4}$ & H & H & 1 & 0.027 \\
\hline $\mathbf{3 3 5}$ & H & H & 1 & 0.027 \\
\hline $\mathbf{3 6}$ & H & H & 1 & 0.027 \\
\hline $\mathbf{3 7}$ & H & H & 1 & 0.027 \\
\hline $\mathbf{3 8}$ & H & H & 1 & 0.057 \\
\hline $\mathbf{3 9}$ & H & H & 1 & 0.031 \\
\hline $\mathbf{4 0}$ & H & H & 1 & 0.031 \\
\hline $\mathbf{4 1}$ & H & H & 1 & 0.035 \\
\hline $\mathbf{4 2}$ & H & H & 1 & 0.027 \\
\hline $\mathbf{4 3}$ & H & H & 1 & 0.027 \\
\hline $\mathbf{4 4}$ & H & H & 1 & 0.027 \\
\hline $\mathbf{4 5}$ & H & H & 1 & 0.053 \\
\hline $\mathbf{4 6}$ & H & H & 1 & 0.053 \\
\hline $\mathbf{4 7}$ & H & H & 1 & 0.032 \\
\hline $\mathbf{4 8}$ & H & H & 1 & 0.032 \\
\hline $\mathbf{4 9}$ & H & H & 1 & 0.069 \\
\hline $\mathbf{5 0}$ & H & HO & 1 & 0.292 \\
\hline $\mathbf{5 1}$ & H & H & 1 & 0.079 \\
\hline $\mathbf{5 2}$ & H & H & 1 & 0.038 \\
\hline $\mathbf{5 3}$ & H & H & 1 & 0.038 \\
\hline $\mathbf{5 4}$ & H & H & 1 & 0.062 \\
\hline $\mathbf{5 5}$ & H & H & 1 & 0.065 \\
\hline $\mathbf{5 6}$ & H & H & 1 & 0.069 \\
\hline $\mathbf{5 7}$ & H & HO & 1 & 0.292 \\
\hline $\mathbf{5 8}$ & H & HO & 1 & 0.292 \\
\hline $\mathbf{5 9}$ & H & HO & 1 & 0.292 \\
\hline & & & & \\
\hline
\end{tabular}

In the final geometry of Sophoraflavanone $\mathrm{G}$ after optimization, all the bonds analyzed were characterized by the predominance of covalence, where we can highlight the bonds $(9,14,21,27$, 30, 48, 55 and 57) between carbon and (45) between carbon and oxygen as second order bonds. In 
addition, the links (16, 19 and 44) between carbons are noted for their rotability (Table 3 ). Complementing the conformational analysis, the largest and smallest angles between joints were identified, angles $18(\mathrm{CCC})$ and $44(\mathrm{HCH})$ with $124.7844^{\circ}$ and $105.4585^{\circ}$ respectively; and the largest and smallest torsion angles, the $147(\mathrm{CCOH})$ and 67 (ACC) systems with $179,999^{\circ}$ and $179,978^{\circ}$ respectively.

Table 3: Properties of the compound Sophoraflavanone G

\begin{tabular}{|c|c|c|c|c|c|c|}
\hline Bond & Type & Initial Atom & Final Atom & Order of Bond & Rotability & Length (̊) \\
\hline 1 & $\mathrm{H}-\mathrm{C}$ & H11 & $\mathrm{C} 8$ & 1 & No & 1.09764 \\
\hline 2 & $\mathrm{H}-\mathrm{C}$ & $\mathrm{H} 13$ & $\mathrm{C} 8$ & 1 & $\mathrm{No}$ & 1.09959 \\
\hline 3 & $\mathrm{C}-\mathrm{H}$ & $\mathrm{C} 8$ & $\mathrm{H} 12$ & 1 & $\mathrm{No}$ & 1.09868 \\
\hline 4 & $\mathrm{C}-\mathrm{C}$ & $\mathrm{C} 8$ & $\mathrm{C} 7$ & 1 & $\mathrm{No}$ & 1.48994 \\
\hline 5 & $\mathrm{H}-\mathrm{C}$ & $\mathrm{H} 14$ & C9 & 1 & No & 1.08640 \\
\hline 6 & $\mathrm{H}-\mathrm{O}$ & H19 & O1 & 1 & $\mathrm{No}$ & 0.95729 \\
\hline 7 & $\mathrm{O}-\mathrm{C}$ & $\mathrm{O} 1$ & $\mathrm{C} 12$ & 1 & $\mathrm{No}$ & 1.36383 \\
\hline 8 & $\mathrm{H}-\mathrm{C}$ & $\mathrm{H} 17$ & $\mathrm{C} 10$ & 1 & No & 1.11472 \\
\hline 9 & $\mathrm{C}-\mathrm{C}$ & $\mathrm{C7}$ & C9 & 2 & $\mathrm{No}$ & 1.33288 \\
\hline 10 & $\mathrm{C}-\mathrm{C}$ & $\mathrm{C} 7$ & C6 & 1 & No & 1.51007 \\
\hline 11 & $\mathrm{C}-\mathrm{H}$ & C9 & H15 & 1 & $\mathrm{No}$ & 1.08735 \\
\hline 12 & $\mathrm{H}-\mathrm{C}$ & $\mathrm{H} 18$ & $\mathrm{C} 13$ & 1 & $\mathrm{No}$ & 1.09731 \\
\hline 13 & $\mathrm{H}-\mathrm{C}$ & $\mathrm{H} 10$ & C6 & 1 & $\mathrm{No}$ & 1.11986 \\
\hline 14 & C-C & $\mathrm{C} 12$ & C13 & 2 & $\mathrm{No}$ & 1.39715 \\
\hline 15 & $\mathrm{C}-\mathrm{C}$ & $\mathrm{C} 12$ & C11 & 1 & No & 1.41671 \\
\hline 16 & $\mathrm{C}-\mathrm{C}$ & $\mathrm{C} 10$ & C6 & 1 & Yes & 1.54326 \\
\hline 17 & C-H & $\mathrm{C} 10$ & H16 & 1 & $\mathrm{No}$ & 1.10721 \\
\hline 18 & C-C & $\mathrm{C} 10$ & C11 & 1 & $\mathrm{No}$ & 1.49830 \\
\hline 19 & C-C & C6 & C5 & 1 & Yes & 1.53482 \\
\hline 20 & C-C & C13 & C14 & 1 & $\mathrm{No}$ & 1.40151 \\
\hline 21 & C-C & C11 & $\mathrm{C} 16$ & 2 & $\mathrm{No}$ & 1.40243 \\
\hline 22 & $\mathrm{H}-\mathrm{C}$ & $\mathrm{H7}$ & $\mathrm{C} 4$ & 1 & No & 1.09800 \\
\hline 23 & C-C & $\mathrm{C} 5$ & $\mathrm{C} 4$ & 1 & No & 1.49010 \\
\hline 24 & $\mathrm{C}-\mathrm{H}$ & $\mathrm{C} 5$ & $\mathrm{H} 9$ & 1 & $\mathrm{No}$ & 1.10954 \\
\hline 25 & $\mathrm{C}-\mathrm{H}$ & $\mathrm{C} 5$ & $\mathrm{H} 8$ & 1 & $\mathrm{No}$ & 1.11037 \\
\hline 26 & $\mathrm{H}-\mathrm{C}$ & H3 & $\mathrm{C} 1$ & 1 & No & 1.09867 \\
\hline 27 & C-C & $\mathrm{C} 4$ & $\mathrm{C} 2$ & 2 & $\mathrm{No}$ & 1.33981 \\
\hline 28 & $\mathrm{H}-\mathrm{C}$ & H1 & C1 & 1 & No & 1.09817 \\
\hline 29 & $\mathrm{C}-\mathrm{O}$ & $\mathrm{C} 14$ & O6 & 1 & $\mathrm{No}$ & 1.35344 \\
\hline 30 & C-C & $\mathrm{C} 14$ & C15 & 2 & No & 1.41535 \\
\hline 31 & $\mathrm{H}-\mathrm{C}$ & H6 & C3 & 1 & No & 1.09926 \\
\hline 32 & C-C & $\mathrm{C} 16$ & $\mathrm{C} 15$ & 1 & $\mathrm{No}$ & 1.41231 \\
\hline 33 & $\mathrm{C}-\mathrm{O}$ & $\mathrm{C} 16$ & $\mathrm{O} 2$ & 1 & No & 1.37387 \\
\hline 34 & $\mathrm{C}-\mathrm{C}$ & $\mathrm{C} 2$ & $\mathrm{C} 1$ & 1 & $\mathrm{No}$ & 1.49037 \\
\hline 35 & C-C & $\mathrm{C} 2$ & C3 & 1 & $\mathrm{No}$ & 1.48967 \\
\hline 36 & C-H & $\mathrm{C} 1$ & $\mathrm{H} 2$ & 1 & No & 1.09843 \\
\hline 37 & $\mathrm{O}-\mathrm{H}$ & O6 & $\mathrm{H} 28$ & 1 & No & 0.96525 \\
\hline
\end{tabular}




\begin{tabular}{|l|l|l|l|l|l|l|}
\hline $\mathbf{3 8}$ & C-C & C15 & C19 & 1 & No & 1.46865 \\
\hline $\mathbf{3 9}$ & O-C & O2 & C17 & 1 & No & 1.44214 \\
\hline $\mathbf{4 0}$ & C-H & C3 & H4 & 1 & No & 1.09808 \\
\hline $\mathbf{4 1}$ & C-H & C3 & H5 & 1 & No & 1.09912 \\
\hline $\mathbf{4 2}$ & H-C & H20 & C17 & 1 & No & 1.11651 \\
\hline $\mathbf{4 3}$ & C-C & C17 & C20 & 1 & No & 1.51063 \\
\hline $\mathbf{4 4}$ & C-C & C17 & C18 & 1 & Yes & 1.53432 \\
\hline $\mathbf{4 5}$ & C-O & C19 & O3 & 2 & No & 1.22776 \\
\hline $\mathbf{4 6}$ & C-C & C19 & C18 & 1 & No & 1.51014 \\
\hline $\mathbf{4 7}$ & H-C & H23 & C21 & 1 & No & 1.09951 \\
\hline $\mathbf{4 8}$ & C-C & C20 & C21 & 2 & No & 1.39864 \\
\hline $\mathbf{4 9}$ & C-C & C20 & C25 & 1 & No & 1.40746 \\
\hline $\mathbf{5 0}$ & C-C & C21 & C22 & 1 & No & 1.38722 \\
\hline $\mathbf{5 1}$ & C-H & C18 & H21 & 1 & No & 1.10900 \\
\hline $\mathbf{5 2}$ & C-H & C18 & H22 & 1 & No & 1.10734 \\
\hline $\mathbf{5 3}$ & O-C & O4 & C25 & 1 & No & 0.95111 \\
\hline $\mathbf{5 4}$ & O-H & O4 & H26 & 1 & No & 1.40272 \\
\hline $\mathbf{5 5}$ & C-C & C25 & C24 & 2 & No & 1.09593 \\
\hline $\mathbf{5 6}$ & C-H & C22 & H24 & 1 & No & 1.40282 \\
\hline $\mathbf{5 7}$ & C-C & C22 & C23 & 2 & No & 1.39912 \\
\hline $\mathbf{5 8}$ & C-C & C24 & C23 & 1 & No & 1.09769 \\
\hline $\mathbf{5 9}$ & C-H & C24 & H25 & 1 & 1.36708 \\
\hline $\mathbf{6 0}$ & C-O & C23 & O5 & H27 & 1 & 0.95122 \\
\hline $\mathbf{6 1}$ & O-H & O5 & & & \\
\hline
\end{tabular}

\section{Electronic Characterization and Reactivity Descriptors}

After geometric optimization, the molecule a theoretically more stable structure, it was possible to calculate the atomic charges using the most traditional and known method among chemists: the Mulliken Population Analysis [51] This method divides the charge density between two atoms evenly without taking into account electronegativity; Atomic charges are useful in the correlational study between the structure of the molecule and its biological activity [52][53].The calculations under the PM3 formalism how us that (TABLE 4) there was a large variation between the atomic charges of atoms of the same element, the oxygen with the highest load was $\mathrm{O} 18$ with -0.1916 while the lowest oxygen, O14 with -0.3783 , varied 0.1867 charge; the carbons of the same form being the one with the highest load C21 with 0.4041 and the one with the lowest load C15 with 0.4321 , varying 0.0280 ; for hydrogen, the atomic charges ranged from 0.1006 in hydrogen $\mathrm{H} 44$ to 0.2858 in hydrogen $\mathrm{H} 59$, ranging from 0.1543 .

Table 4: Population Analysis of Mulliken for Sophoraflavanone G

\begin{tabular}{|c|c|c|c|c|c|}
\hline Atom & Charge & Atom & Charge & Atom & Charge \\
\hline 01 C & -0.2643 & 21 C & 0.4041 & 41 H & 0.1450 \\
\hline 02 C & -0.1268 & 22 O & -0.3783 & $\mathbf{4 2 ~ H}$ & 0.1122 \\
\hline 03 C & -0.2719 & 23 C & -0.1956 & $\mathbf{4 3 ~ H}$ & 0.1204 \\
\hline 04 C & -0.2520 & 24 C & -0.1027 & $\mathbf{4 4 ~ H}$ & 0.1006 \\
\hline 05 C & -0.2015 & 25 C & -0.2695 & $\mathbf{4 5 ~ H}$ & 0.1700 \\
\hline
\end{tabular}




\begin{tabular}{|c|c|c|c|c|c|}
\hline $06 \mathrm{C}$ & -0.1039 & $26 \mathrm{C}$ & 0.1366 & $46 \mathrm{H}$ & 0.1704 \\
\hline $07 \mathrm{C}$ & -0.1336 & $27 \mathrm{C}$ & -0.3878 & $47 \mathrm{H}$ & 0.1558 \\
\hline $08 \mathrm{C}$ & -0.2637 & $28 \mathrm{C}$ & 0.1475 & $48 \mathrm{H}$ & 0.1035 \\
\hline $09 \mathrm{C}$ & -0.3302 & 290 & -0.2421 & $49 \mathrm{H}$ & 0.2480 \\
\hline $10 \mathrm{C}$ & -0.1661 & 300 & -0.2337 & $50 \mathrm{H}$ & 0.2396 \\
\hline $11 \mathrm{C}$ & -0.2880 & 310 & -0.2675 & $51 \mathrm{H}$ & 0.1569 \\
\hline $12 \mathrm{C}$ & 0.2022 & $32 \mathrm{H}$ & 0.1085 & $52 \mathrm{H}$ & 0.1675 \\
\hline $13 \mathrm{C}$ & -0.3676 & $23 \mathrm{H}$ & 0.1118 & $53 \mathrm{H}$ & 0.1796 \\
\hline $14 \mathrm{C}$ & 0.2614 & $34 \mathrm{H}$ & 0.1121 & $54 \mathrm{H}$ & 0.2112 \\
\hline $15 \mathrm{C}$ & -0.4321 & $35 \mathrm{H}$ & 0.1125 & $55 \mathrm{H}$ & 0.2237 \\
\hline $16 \mathrm{C}$ & 0.2453 & $36 \mathrm{H}$ & 0.1116 & $56 \mathrm{H}$ & 0.2039 \\
\hline 170 & -0.2391 & $37 \mathrm{H}$ & 0.1185 & $57 \mathrm{H}$ & 0.2292 \\
\hline 180 & -0.1916 & $38 \mathrm{H}$ & 0.1911 & $58 \mathrm{H}$ & 0.2237 \\
\hline $19 \mathrm{C}$ & 0.0807 & $39 \mathrm{H}$ & 0.1376 & $59 \mathrm{H}$ & 0.2858 \\
\hline $20 \mathrm{C}$ & -0.3491 & $40 \mathrm{H}$ & 0.1301 & & \\
\hline
\end{tabular}

To identify the areas of higher nucleophilicity and electrophilicity of the molecule, the electrostatic potential map (MESP) was calculated; MESP was plotted by mapping the electrostatic potential surface (Figures 3 ) on the electron density surface (Figures 4). Thus by analyzing the electrostatic potential map of the compound Sophoraflavanone G (Figure 5) we can identify a higher concentration of electrons, nucleophilic region (in red), in the areas where oxygen is located (O17, O18, O22, O29, O30 and O31). ), but the rest of the structure has electron deficiency, electrolyte region (in white), except in the regions where the rings and cycles formed by the carbons that remain in a neutral area (dark blue and light blue) are located [54][55][56].

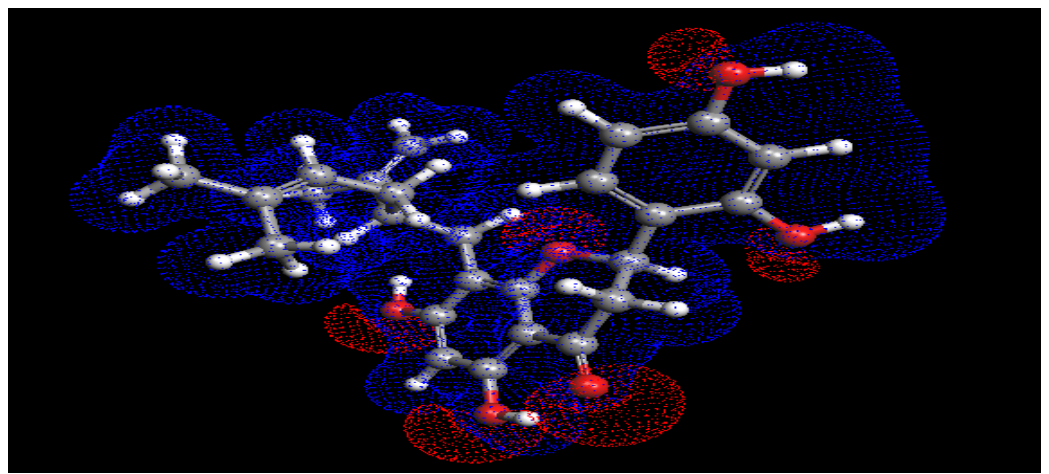

Figure 3: Superfície de Potencial Eletrostático do Sophoraflavanone G

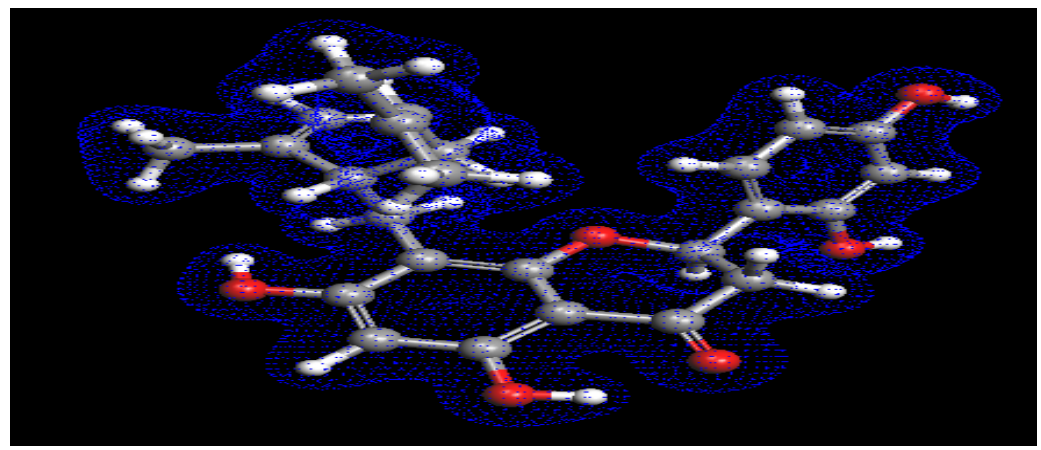

Figure 4: Sophoraflavanone G Electronic Density Surface 


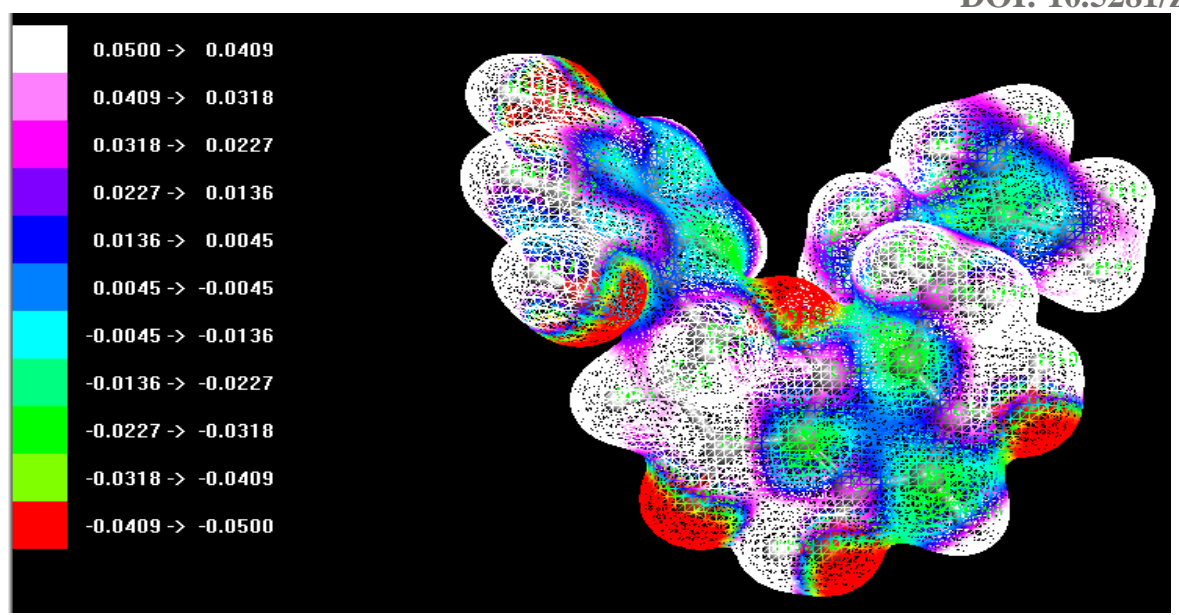

Figure 5: Electrostatic potential map of Sophoraflavanone G

Global reactivity descriptors act as a bridge between structural stability and global chemical reactivity [57]. This is also information about fundamental characteristics of chemical reactivity, such as ionization potential, electron affinity, electronegativity, chemical potential, global hardness and global softness (Table 3) [24]. The LCAO-MO Model used in the theory of molecular orbitals uses the linear combination of atomic orbitals to generate the molecular orbitals, keeping the same number of orbitals. frontier orbitals, because from the energy difference between them we can identify the electron receptor or donor tendency of the molecule. A good starting point for determining these parameters is the energetic values of the frontier molecular orbitals (HOMO and LUMO) that are used in reactivity [18], as they provide information about the electron-donor character (HOMO) and /or electron-acceptor (LUMO) of a compound [58][59]. The studied molecule presented HOMO (figure 6) $(-9,02585 \mathrm{eV})$ with the atoms $(\mathrm{C} 6, \mathrm{C} 11, \mathrm{C} 13, \mathrm{C} 14, \mathrm{C} 15$, C16, $\mathrm{O} 18$ and O31) and LUMO(Figures 7) $(-5.14186 \mathrm{eV})$ being highlighted (C12, C13, C14, C15 , C16, C21, O17, O18, O22, O31). The difference between HOMO-LUMO energy values is of utmost importance as a determinant of chemical stability. The molecules have broadband gaps, which are generally stable and nonreactive. Those with smaller bandwidths are reactive as it facilitates interaction with reagents [60][61][50].In addition, the GAP (amount of energy required for the electron to make a transition) is calculated on the energy difference between HOMO and LUMO (1).

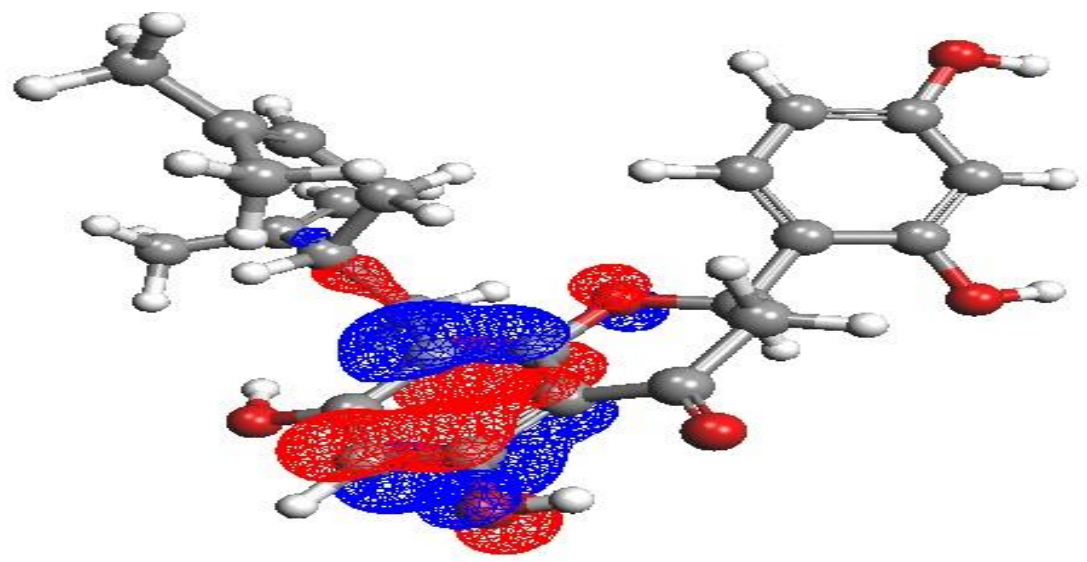

Figure 6: Highest energy occupied molecular orbital ( HOMO) of Sophoraflavanone G 


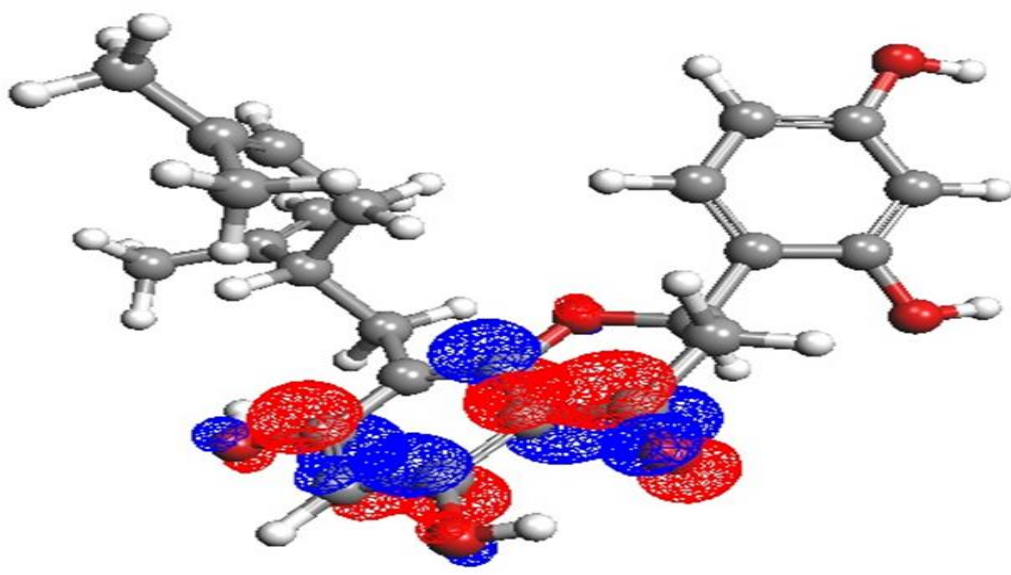

Figure 7: lower energy unoccupied molecular orbital (LUMO) of Sophoraflavanone G

The difference between HOMO-LUMO energy values is of utmost importance as a determinant of chemical stability. The molecules have broadband gaps, which are generally stable and nonreactive. Those with smaller bandwidths are reactive as it facilitates interaction with reagents [60][61][50].In addition, the GAP (amount of energy required for the electron to make a transition) is calculated on the energy difference between HOMO and LUMO (1). Comparing Sophoraflavanone with its reference compound Naringenin, it was possible to observe some differences that are fundamental in characterization. For example, Sophoraflavanone $G$ has been shown to be a molecule that tends to donate electrons by presenting HOMO $(-9,02585 \mathrm{eV})$ higher than Naringenin $(-9,2525 \mathrm{eV})$ (figure 8).

Table 5 shows the reactivity parameters of the compound Sophoraflavanone G and the compound Naringenin, which were obtained by calculations using the molecular orbital energies HOMO and LUMO. Regarding the energy required to remove an electron (ionization potential), Sophoraflavanone had a lower ionization potential $(9,02585 \mathrm{eV})$ than Naringenin $(9,25325 \mathrm{eV})$, indicating to be more stable. Having the energy of the frontier orbitals as a reference, the hardness $(\eta)$ and softness (S) values in the study of Pearson's theory (HSAB, hard and soft acid and bases) [26][62] These are fundamental concepts for understanding the acid / base behavior of molecules, where we can simplify molecules with a donor / recipient center of small electron pairs (with a low tendency to be polarizable), are indicative of favoring electrostatic interactions being considered. hard acids (receptors) or bases (donors). Molecules that favor the interaction of the frontier orbitals, that is, with low energy value, are indicative of high polarizability, since in general they have high reactivity sites (donor / receptor sites of electron pairs) and are considered as bases (donors) or soft acids (receptors), thus having high reactivity[63]. That is, Interactions between for hard acids / bases, or soft acids / bases tend to form more stable complexes when compared to the interaction between soft acids and hard bases or hard acids and bases soft [64][21]. Regarding hardness and softness, Sophoraflavanone tends to have difficulty being deformed, this is proven by observing that it had higher hardness and less softness compared to Naringenin. 
NARIGENIN

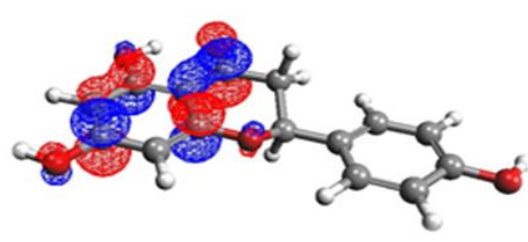

LUMO $=-6.26133$

$\Delta \mathrm{E}=2.99192$

$\mathrm{HOMO}=-9.25325$

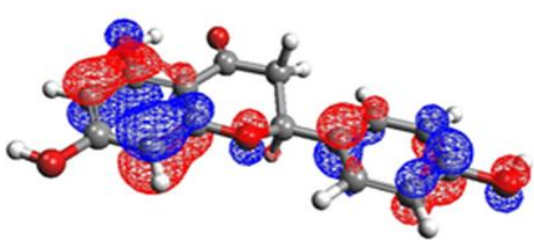

DOI: 10.5281/zenodo.3562943 SOPHORAFLAVONE G

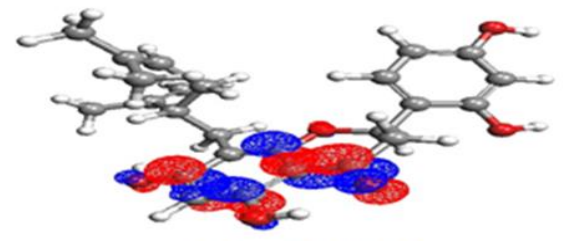

LUMO $=-5.14186$

$\Delta \mathrm{E}=3.88399$

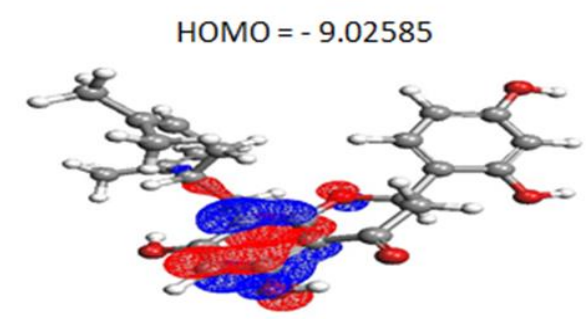

Figure 8: GAP of Narigenin and Sophoraflavanone G

Table 5: Global Reactivity Descriptors calculated for Sophoraflavanone G

\begin{tabular}{|c|c|c|}
\hline Descriptor & Sophoraflavanone G & Naringenin \\
\hline HOMO & $-9.02585 \mathrm{eV}$ & $-9.25325 \mathrm{eV}$ \\
\hline LUMO & $-5.14186 \mathrm{eV}$ & $-6.26133 \mathrm{eV}$ \\
\hline GAP & $3.88399 \mathrm{eV}$ & $2.99192 \mathrm{eV}$ \\
\hline Electron affinity $(\mathrm{A})$ & $5.14186 \mathrm{eV}$ & $6.26133 \mathrm{eV}$ \\
\hline Electronegativity $(\chi)$ & $7.08385 \mathrm{eV}$ & $7.75729 \mathrm{eV}$ \\
\hline Vertical Ionization potential $(\mathrm{I})$ & $9.02585 \mathrm{eV}$ & $9.25325 \mathrm{eV}$ \\
\hline Chemical hardness $(\eta)$ & $1.94199 \mathrm{eV}$ & $1.49596 \mathrm{eV}$ \\
\hline Chemical softness $(\mathrm{S})$ & $0.25747 \mathrm{eV}$ & $0.33423 \mathrm{eV}$ \\
\hline Chemical potential $(\mu)$ & $-7.08385 \mathrm{eV}$ & $-7.75729 \mathrm{eV}$ \\
\hline Electrophilicity index $(\Omega)$ & $12.91994 \mathrm{eV}$ & $20.11269 \mathrm{eV}$ \\
\hline
\end{tabular}

Pharmacokinetic and pharmacological parameters of absorption, distribution, metabolism, excretion and toxicity -Admet

Due to the search for new drugs with greater specificity, it has been fostered by the development of computational algorithms, which allow simulating receptor drug interaction (molecular docking)[65] [66][67][68][69], as well as predicting pharmacokinetics, being able to identify within of a set of molecules those that can become an efficient drug with fewer side effects. The mechanisms use molecular descriptors, which adjusted within facings (models) and rules allow the structures to be quickly related to ADME properties, especially in relation to biological barriers, intestinal absorption [42][70][71][71]. 
The chemical structure of Sophoraflavanone $G$ was subjected to ADMET in silico screening using SwissADME online software to predict overall absorption, distribution, metabolism, excretion and toxicity hazards. In the silico evaluation, we analyzed different descriptors that were calculated, partition coefficient (octanol / water), molecular weight (424.49 g / mol), number of H+ donor groups and acceptor groups that compounded moderate solubility. in water. Absorption or permeation of a molecule is more likely when the molecular weight is below the $\log \mathrm{P}$ value is less than 5 and the value. Sophoraflavonone $\mathrm{G}$ has a maximum of $6 \mathrm{H}+$ donors and $4 \mathrm{H}+$ acceptor atoms, as shown in Figure 9. According to its pharmacokinetic properties, Sophoraflavanone G showed a high level of gastrointestinal adsorption which contributes to good oral bioavailability.

Sophoraflavanone $\mathrm{G}$ according to pharmacokinetic parameters evaluated in silico showed no inhibition of cytochrome P450 isomers and glycoprotein P with CYP2C9 isomer exemption. Prediction of similarity with other drugs was also performed according to Ghose and Veber rules and the molecule has characteristics of bioavailability [38].

Thus, the screening process with the Lipinski Rule showed that there were no compound violations, as the screening process with Ghose rules shows that the substance sophoraflavonone $\mathrm{G}$ can be accepted for not showing violations of drug similarity rules (figure 10).

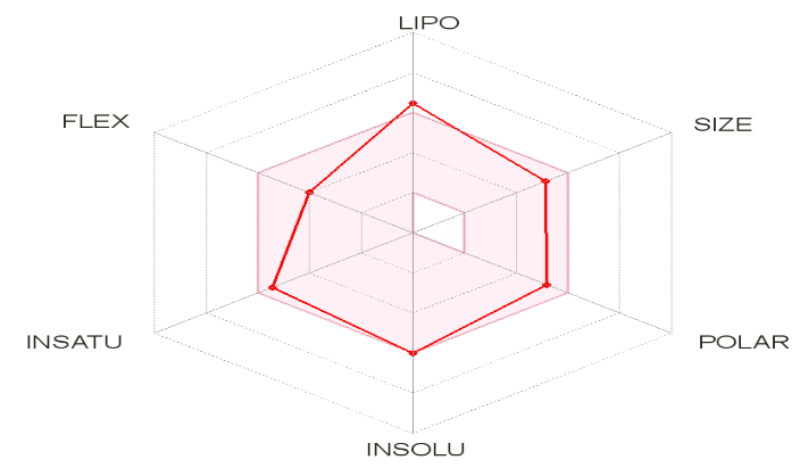

Figure 9: Biovailability and pharmacokinetic parameters Sophoraflavanone G using Swiss ADME.

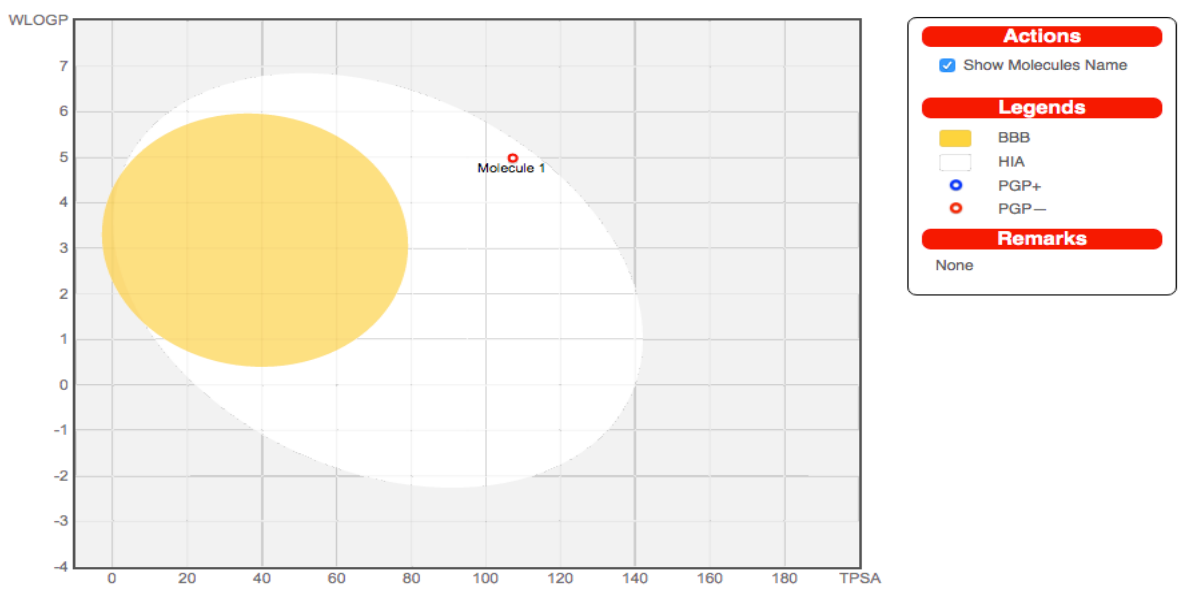

Figure 10: Brain or intestinal permeability map based on BOILED - Egg model for Sophoraflavanone G 


\section{Virtual Screening for Target Classes}

An important data for the development of a new drug is the evaluation of interactions with possible biological targets, and may be a descriptor for the therapeutic improvement [72]. Regarding possible biological target classes, Sophoraflavanone $\mathrm{G}$ had a higher probability of interactions with enzymes (20\%), hydrolases (13.3\%) and nuclear receptor (13.3\%) (Figure 11). Regarding specific targets, it presented a higher probability $(>0.5)$ of interaction with Estrogen receptor alpha, Sodium / glucose cotransporter 2, Beta-secretase 1, Cyclooxygenase-1, which were ranked the best binging probability on the SwissTarget Prediction report (Table 6).

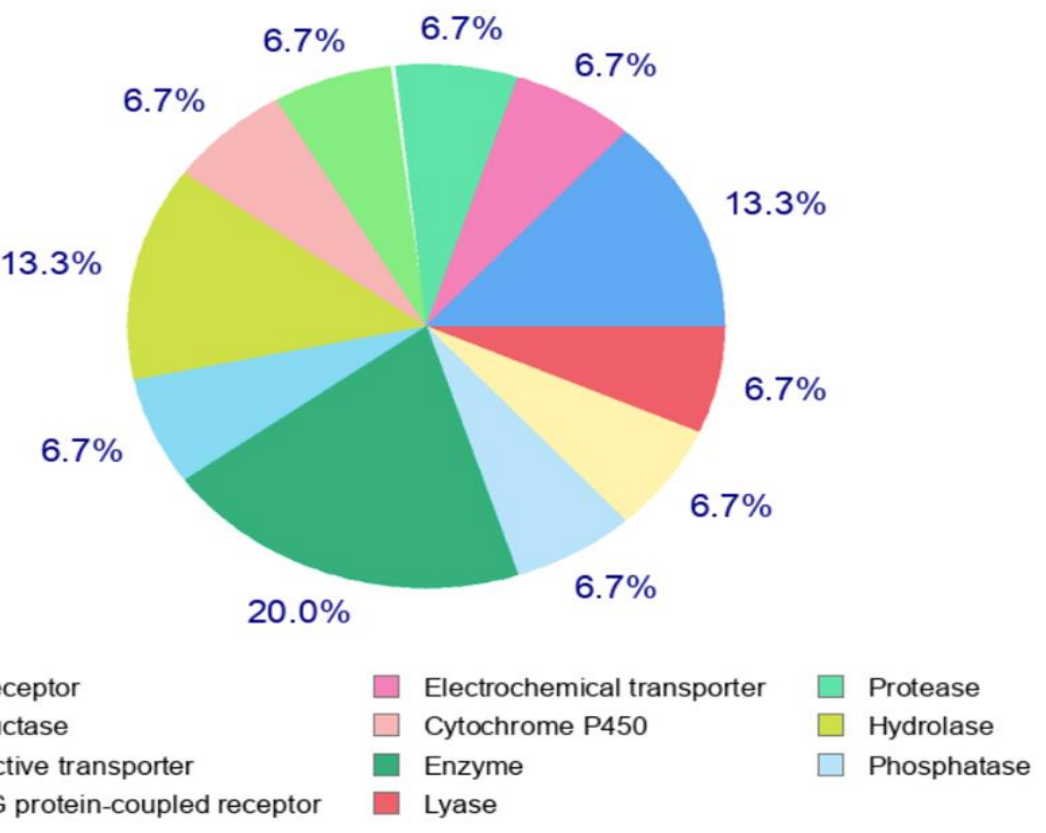

Figure 11: Virtual Screening for Target Classes for Sophoraflavanone G

Table 6: Best binging probability on the SwissTarget Prediction report for Sophoraflavanone G

\begin{tabular}{|l|l|l|l|}
\hline \multicolumn{1}{|c|}{ TARGET } & $\begin{array}{c}\text { Common } \\
\text { name }\end{array}$ & \multicolumn{1}{|c|}{ Target Class } & \multicolumn{1}{|c|}{ Probability* } \\
\hline Estrogen receptor alpha & ESR1 & Nuclear receptor & 0.649778524356 \\
\hline $\begin{array}{l}\text { Sodium/glucose cotransporter } \\
2\end{array}$ & SLC5A2 & $\begin{array}{l}\text { Electrochemical } \\
\text { transporter }\end{array}$ & 0.625678935906 \\
\hline Beta-secretase 1 & BACE1 & Protease & 0.625678935906 \\
\hline Cyclooxygenase-1 & PTGS1 & Oxidoreductase & 0.553263465898 \\
\hline Estrogen receptor beta & ESR2 & Nuclear receptor & 0.183235381136 \\
\hline
\end{tabular}




\begin{tabular}{|l|l|l|l|}
\hline Cytochrome P450 19A1 & CYP19A1 & Cytochrome P450 & 0.143014512691 \\
\hline Butyrylcholinesterase & BCHE & Hydrolase & 0.143014512691 \\
\hline Acetylcholinesterase & ACHE & Hydrolase & 0.143014512691 \\
\hline $\begin{array}{l}\text { ATP-binding cassette sub- } \\
\text { family G member 2 }\end{array}$ & ABCG2 & $\begin{array}{l}\text { Primary active } \\
\text { transporter }\end{array}$ & 0.126928723833 \\
\hline $\begin{array}{l}\text { Estradiol 17-beta- } \\
\text { dehydrogenase 1 }\end{array}$ & HSD17B1 & Enzyme & 0.118883306718 \\
\hline $\begin{array}{l}\text { Protein-tyrosine phosphatase } \\
\text { B }\end{array}$ & PTPN1 & Phosphatase & 0.118883306718 \\
\hline Phospholipase A2 group 1B & PLA2G1B & Enzyme & 0.118883306718 \\
\hline Adenosine A1 receptor & ADORA1 & $\begin{array}{l}\text { Family A G protein- } \\
\text { coupled receptor }\end{array}$ & 0.118883306718 \\
\hline Carboxylesterase 2 & CES2 & Enzyme & 0.118883306718 \\
\hline Carbonic anhydrase VII & CA7 & Lyase & 0.118883306718 \\
\hline
\end{tabular}

\section{Conclusions}

The molecular structure of Sophoraflavanone $\mathrm{G}$ was geometrically optimized by semi-empirical quantum calculations, obtaining the thermodynamically more stable structure. Through the electrostatic potential map it was possible to identify the areas where the nucleophilic bonds will occur that comprise the whole area of oxygen. Due to geometrization one can also obtain the atomic charges of Mulliken for the atoms of $\mathrm{O}, \mathrm{C}, \mathrm{H}$ highlighting the variation of charges between atoms of the same species.

Regarding the frontier orbitals, it was possible to identify a greater tendency to donate electrons compared to Naringeni, having a lower ionization potential, with greater hardness and less softness. Sophoraflavonone G drug confirmed the safety of the compound for oral administration. It also has good skin permeability which enables applications in topical formulations. However, it lacks the blood-brain barrier permeability. It is a highly selective structure that protects the Central Nervous System (CNS) from potentially neurotoxic substances present in the blood and is essential for normal metabolic function of the brain, yet has indications of intestinal gastro absorption. Regarding possible interactions with biological targets, it was more likely to interact with Estrogen receptor alpha, Sodium / glucose cotransporter 2, Beta-secretase 1, Cyclooxygenase-1. 
The data obtained constitute an initial step for a comparative analysis between its analogues and fundamental for future studies of relationships between the three-dimensional structure of Sophoraflavanone $\mathrm{G}$ and its biological activities.

\section{Acknowledgements}

The present work was partially funded by $\mathrm{CNPq}$ - National Council for Scientific and Technological Development and CAPES - Brazilian Federal Agency for Support and Evaluation of Postgraduate Education of the Brazilian Ministry of Education.

\section{References}

[1] F. Galeotti, E. Barile, P. Curir, M. Dolci, and V. Lanzotti, "Flavonoids from carnation (Dianthus caryophyllus) and their antifungal activity," Phytochem. Lett., 2008.

[2] M. Kuroyanagi, T. Arakawa, Y. Hirayama, and T. Hayashi, "Antibacterial and antiandrogen flavonoids from Sophora flavescens," J. Nat. Prod., 1999.

[3] C. Y. Hsiang, C. L. Hsieh, S. L. Wu, L. Lu, T. Y. Lai, and Ho, "Inhibitory effect of anti-pyretic and anti-inflammatory herbs on herpes simplex virus replication," Am. J. Chin. Med., 2001.

[4] Y. C. Kim et al., "Antimalarial activity of lavandulyl flavanones isolated from the roots of Sophora flavescens," Biol. Pharm. Bull., 2004.

[5] A. De Naeyer, W. Vanden Berghe, V. Pocock, S. Milligan, G. Haegeman, and D. De Keukeleire, "Estrogenic and anticarcinogenic properties of kurarinone, a lavandulyl flavanone from the roots of Sophora flavescens," J. Nat. Prod., 2004.

[6] S. Dai, M. Y. Chan, S. S. Lee, and C. W. Ogle, "The antiarrhythmic effects of Sophora flavescens Ait. in rats and mice.," Am. J. Chin. Med., 1986.

[7] T. H. Kang et al., "Cytotoxic lavandulyl flavanones from Sophora flavescens," J. Nat. Prod., 2000.

[8] Z. X. Yang et al., "Isolation of antibacterial activity constituents of total flavonoids from sophora flavescens and simultaneous determination of seven flavonoids by HPLC," Chinese Pharm. J., 2016.

[9] K. C. Jang, S. C. Kim, E. Y. Song, and Y. C. Um, "Isolation and identification of antibacterial and anticancer substances from roots of Sophora flavescens Aiton," in Acta Horticulturae, 2008.

[10] M. Tashiro et al., "Effects of isoflavones from Sophora species on the growth and activation of a mouse macrophage-like cell line," Anticancer Res., 2002.

[11] V. Cechinel Filho, F. De Campos, R. Corrêa, R. A. Yunes, and R. J. Nunes, "Aspectos químicos e potencial terapêutico de imidas cíclicas: Uma revisão da literatura," Quimica Nova. 2003.

[12] L. Cláudio, M. M. Marinho, and E. Silva, "In Silico Study of Antiparkinson Drug Levodopa and Drug Design of Four Theoretical Analogues,” Int. J. Recent Res. Rev., vol. X, no. 4, pp. 24-28, 2017.

[13] G. B. de Oliveira Filho et al., "Structural design, synthesis and pharmacological evaluation of thiazoles against Trypanosoma cruzi," Eur. J. Med. Chem., 2017.

[14] C. M. R. Sant'Anna, "Molecular modeling methods in the study and design of bioactive compounds: An introduction," Rev. Virtual Química, vol. 1, no. 1, 2009.

[15] M. Reges, M. M. Marinho, and E. S. Marinho, "Structural Characterization of the Hypoglycemic Drug Glimepiride,” Int. J. Recent Res. Rev., vol. XI, no. 2, pp. 26-35, 2018.

[16] M. A. Thompson, "ArgusLab 401. Planaria Software LLC, Seattle, WA. ArgusLab 4.0. 1." Seattle, 2010.

[17] J. Mancuso and R. J. McEachern, "Applications of the PM3 semi-empirical method to the study of triethylenediamine," J. Mol. Graph. Model., 1997. 
[18] G. Zhang and C. B. Musgrave, "Comparison of DFT Methods for Molecular Orbital Eigenvalue Calculations * Author for correspondence. Email : chasm@stanford.edu,” J. Phys. Chem. A, pp. 1554-1561, 2007.

[19] S. S. Carneiro, M. M. Marinho, and E. S. Marinho, "Electronic / Structural Characterization of Antiparkinsonian Drug Istradefylline : A Semi-Empirical Study,” Int. J. Recent Res. Rev., vol. X, no. 4, pp. 9-14, 2017.

[20] S. Suresh Kumar, S. Athimoolam, and B. Sridhar, "XRD, vibrational spectra and quantum chemical studies of an anticancer drug: 6-Mercaptopurine," Spectrochim. Acta - Part A Mol. Biomol. Spectrosc., 2015.

[21] D. H. Pereira, F. A. La Porta, R. T. Santiago, D. R. Garcia, and T. C. Ramalho, "New perspectives on the role of frontier molecular orbitals in the study of chemical reactivity: A review," Rev. Virtual Quim., 2016.

[22] K. Fukui, "Role of frontier orbitals in chemical reactions," Science (80-. )., 1982.

[23] T. Koopmans, "Über die Zuordnung von Wellenfunktionen und Eigenwerten zu den Einzelnen Elektronen Eines Atoms," Physica, 1934.

[24] R. G. Parr, R. A. Donnelly, M. Levy, and W. E. Palke, "Electronegativity: The density functional viewpoint," J. Chem. Phys., 1978.

[25] R. G. Parr and R. G. Pearson, "Absolute Hardness: Companion Parameter to Absolute Electronegativity,” J. Am. Chem. Soc., 1983.

[26] R. G. Parr and P. K. Chattaraj, "Principle of Maximum Hardness," J. Am. Chem. Soc., 1991.

[27] H. Chermette, "Chemical reactivity indexes in density functional theory," J. Comput. Chem., 1999.

[28] N. Islam and D. Chandra Ghosh, "A new algorithm for the evaluation of the global hardness of polyatomic molecules," Mol. Phys., 2011.

[29] L. H. Mendoza-Huizar and C. H. Rios-Reyes, "Chemical reactivity of Atrazine employing the Fukui function," J. Mex. Chem. Soc., 2011.

[30] S. Pereira et al., "ELECTRONIC, STRUCTURAL AND PHARMACOCINETIC CHARACTERIZATION OF TRICYCLIC ALKALOID ALTERNAMIDE A: A SEMIEMPIRICAL QUANTUM STUDY AND ADMET,” Int. J. Res. -GRANTHAALAYAH, vol. 7, no. October, pp. 429-447, 2019.

[31] M. D. Hanwell, D. E. Curtis, D. C. Lonie, T. Vandermeerschd, E. Zurek, and G. R. Hutchison, "Avogadro: An advanced semantic chemical editor, visualization, and analysis platform," J. Cheminform., 2012.

[32] V. M. De Oliveira, M. M. Marinho, and E. S. Marinho, "Semi-Empirical Quantum Characterization of the Drug Selexipag: HOMO and LUMO and Reactivity Descriptors," Int. J. Recent Res. Rev., vol. XII, no. 2, pp. 15-20, 2019.

[33] P. T. Okoli et al., "In Silico Study of Phytochemical Chlorogenic Acid: A Semi- Empirical Quantum Study and Adme,” Int. J. Recent Res. Rev., vol. 52, no. 4, pp. 345-357, 2019.

[34] P. T. Okoli et al., "In Silico Study of Phytochemical Chlorogenic Acid: A Semi- Empirical Quantum Study and Adme," Int. J. Recent Res. Rev., vol. 52, no. 4, pp. 345-357, 2019.

[35] A. Daina, O. Michielin, and V. Zoete, "SwissADME: A free web tool to evaluate pharmacokinetics, drug-likeness and medicinal chemistry friendliness of small molecules," Sci. Rep., 2017.

[36] S. A. Wildman and G. M. Crippen, "Prediction of physicochemical parameters by atomic contributions," J. Chem. Inf. Comput. Sci., 1999.

[37] C. A. Lipinski, F. Lombardo, B. W. Dominy, and P. J. Feeney, "Experimental and computational approaches to estimate solubility and permeability in drug discovery and development settings," Advanced Drug Delivery Reviews. 2012.

[38] D. F. Veber, S. R. Johnson, H. Y. Cheng, B. R. Smith, K. W. Ward, and K. D. Kopple, "Molecular properties that influence the oral bioavailability of drug candidates," J. Med. Chem., 2002.

[39] A. Daina and V. Zoete, "A BOILED-Egg To Predict Gastrointestinal Absorption and Brain Penetration of Small Molecules," ChemMedChem, 2016. 
[40] G. L. Amidon et al., "ChemAxon`s Calculator Plugins," ChemAxon, 2008.

[41] N. M. O’Boyle, M. Banck, C. A. James, C. Morley, T. Vandermeersch, and G. R. Hutchison, "Open Babel: An Open chemical toolbox," J. Cheminform., 2011.

[42] D. Gfeller, A. Grosdidier, M. Wirth, A. Daina, O. Michielin, and V. Zoete, "SwissTargetPrediction: A web server for target prediction of bioactive small molecules," Nucleic Acids Res., 2014.

[43] A. Daina, O. Michielin, and V. Zoete, "SwissTargetPrediction: updated data and new features for efficient prediction of protein targets of small molecules," Nucleic Acids Res., 2019.

[44] D. Gfeller, O. Michielin, and V. Zoete, "Shaping the interaction landscape of bioactive molecules," Bioinformatics, 2013.

[45] C. A. H. Roberto, E. S. Marinho, and O. S. Campos, "Neo-Chlorogenic Acid: Conformatinal and Molecular Analysis by Semi-Empirical Methods,” Int. J. Recent Res. Rev., vol. XII, no. 2, pp. 2126, 2019.

[46] M. Reges, M. M. Marinho, and E. S. Marinho, "Semi-Empirical Study of the Drug Riociguat, an Important Drug for Oral Treatment against Chronic Thromboembolic Pulmonary Hypertension," Int. J. Sci. Eng. Sci., vol. 1, no. 1, pp. 13-17, 2017.

[47] F. N. M. Lucio et al., "Semi-Empirical Study Of Rotenone Stemonone: HOMO, LUMO and Reactivity Descriptors,” Int. J. Sci. Eng. Res., 2019.

[48] E. S. Marinho, "A DFT study of synthetic drug topiroxostat: MEP, HOMO, LUMO," Int. J. Sci. Eng. Res., vol. 7, no. July, pp. 1264-1270, 2016.

[49] C. Henrique et al., "Characterization of the natural insecticide methylcytisine: An in silico study using classic force field,” Int. J. Recent Res. Rev., vol. XII, no. 2, pp. 15-20, 2019.

[50] S. S. Carneiro, A. R. Lima, M. M. Marinho, and E. S. Marinho, "In silico Study Of The Therapeutic Agent In The Treatment Of Non-Hodgkin 's Lymphomas, Peripheral T-Cell Belinostat , A SemiEmpirical Approach,” Imp. J. Interdiscip. Res., no. 8, pp. 1645-1648, 2016.

[51] R. S. Mulliken, "Electronic population analysis on LCAO-MO molecular wave functions. I," J. Chem. Phys., 1955.

[52] S. Sumathi, K. Viswanathan, and S. Ramesh, "FT-IR , FT-Raman and SERS Spectral Studies , HOMO-LUMO Analyses, Mulliken Population Analysis and Density Functional Theoretical Analysis of 1-Chloro 4-Fluorobenzene," IOSR J. Appl. Phys., vol. 8, no. 1, pp. 16-25, 2016.

[53] E. J. Braga, B. T. Corpe, M. M. Marinho, and E. S. Marinho, "Molecular electrostatic potential surface, HOMO-LUMO, and computational analysis of synthetic drug Rilpivirine," Int. J. Sci. Eng. Res., vol. 7, no. 7, pp. 315-319, 2016.

[54] L. Paes, M. M. Marinho, and E. S. Marinho, "QUANTUM STUDY OF GEOMETRIC PROPERTIES OF THE ANTI- HIVCOUMARIN HERACLENOL : A STUDY OF DENSITY FUNCTIONAL,” Int. J. Eng. Technol. Res. Manag., vol. 2, no. 02, pp. 27-37, 2018.

[55] J. J. P. Stewart, "Optimization of parameters for semiempirical methods VI: More modifications to the NDDO approximations and re-optimization of parameters," J. Mol. Model., 2013.

[56] E. S. Marinho, "UTILIZAÇÃO DO MÉTODO SEMI-EMPÍRICO PM7 PARA CARACTERIZAÇÃO DO FÁRMACO ATALURENO : HOMO ,” Rev. Expressão Católica, vol. 1, no. 1, pp. 177-184, 2016.

[57] P. W. Atkins, T. Overton, J. Rourke, M. Weller, F. Armstrong, and M. Hagerman, Shriver \& Atkins' Inorganic Chemistry. 2010.

[58] M. Aurélio, C. De Oliveira, M. M. Marinho, and S. Marinho, "UTILIZAÇÃO DO MÉTODO QUÂNTICO PM7 PARA CARACTERIZAÇÃO DO ROTENOIDE DEGUELINA: UM AGENTE CONTRA O AEDES AEGYPTI," JOIN, no. 1, 2017.

[59] A. B. F. Silva, M. M. Marinho, and F. R. D. S. , Mendes, "In Silico Study of Phytochemical Chlorogenic Acid : A Semi- Empirical Quantum Study and Adme," Int. J. Recent Res. Rev., vol. XII, no. 2, pp. 34-39, 2019.

[60] P. Atkins and R. Friedman, "Molecular Quantum Mechanics Fourth Edition," Oxford Univ. Press New York, 2005. 
[61] P. Atkins and J. De Paula, Atkins' physical chemistry / Peter Atkins, Julio de Paula. 2010.

[62] H. Fujimoto and S. Satoh, "Orbital interactions and chemical hardness," J. Phys. Chem., 1994.

[63] R. G. Pearson, "Absolute Electronegativity and Hardness: Applications to Organic Chemistry," J. Org. Chem., 1989.

[64] M. L. A. A. Vasconcellos, "Pearson's theory for organic chemistry courses: A practical and theoretical exercise applied in the classroom," Quim. Nova, 2014.

[65] A. R. Lima, J. Silva, L. L. Bezerra, M. M. Marinho, and E. S. Marinho, "Molecular docking of potential curcuminoids inhibitors of the NS1 protein of dengue virus," Int. J. Sci. Eng. Res., vol. 8, no. 4, 2017.

[66] J. Silva, A. R. Lima, L. L. Bezerra, M. M. Marinho, and E. S. Marinho, "Molecular coupling study between the potential inhibitor of dengue fever, Annatto and Protein E (DENV-4)," Int. J. Sci. Eng. Res. Vol., vol. 8, no. 7, pp. 815-821, 2017.

[67] K. M. Elokely and R. J. Doerksen, "Docking challenge: Protein sampling and molecular docking performance," J. Chem. Inf. Model., 2013.

[68] J. Silva, A. R. Lima, L. L. Bezerra, M. M. Marinho, and E. S. Marinho, "Bixinoids potentially active against dengue virus: a molecular docking study," JInternational J. Sci. Eng. Res., vol. 8, no. 4, pp. 882-887, 2017.

[69] J. Silva, M. M. Marinho, and E. S. Marinho, "Comparative Study of Molecular Docking Between the Carotenoid Bixin and HIV Inhibitor Protease Indinavir," Int. J. Recent Res. Rev., vol. XI, no. 2, pp. 18-25, 2018.

[70] J. Hodgson, "ADMET - turning chemicals into drugs," Nat. Biotechnol., 2001.

[71] J. Vora et al., "Molecular docking, QSAR and ADMET based mining of natural compounds against prime targets of HIV," J. Biomol. Struct. Dyn., 2019.

[72] H. Geppert, M. Vogt, and J. Bajorath, "Current trends in ligand-based virtual screening: molecular representations, data mining methods, new application areas, and performance evaluation," J. Chem. Inf. Model., 2010.

\footnotetext{
*Corresponding author.

E-mail address: emmanuel.marinho @uece.br
} 